\title{
(2) OPEN ACCESS \\ Interrupted time series analysis of cannabis coding in Colorado during the ICD-10-CM transition
}

\author{
Katelyn E Hall (D) ,' Hannah Yang (D) ,' DeLayna Goulding, ${ }^{1}$ Elyse Contreras, ${ }^{1}$ \\ Katherine $\mathrm{A} \mathrm{James}^{3}$
}

- Additional material is published online only. To view, please visit the journal online (http://dx.doi.org/10.1136/ injuryprev-2019-043511).

${ }^{1}$ Marijuana Health Monitoring Program, Colorado Department of Public Health and

Environment, Denver, Colorado, USA

${ }^{2}$ EMS and Trauma Systems Section, Montana Department of Public Health and Human Services, Helena, Montana, USA ${ }^{3}$ Colorado School of Public Health, University of Colorado Denver Graduate School, Aurora, Colorado, USA

\section{Correspondence to}

Hannah Yang, EMS and Trauma Systems Section, Montana Department of Public Health and Human Services, Helena, MT 59620, USA; HANNAH. YANG@MT.GOV

Received 28 January 2020 Revised 18 November 2020 Accepted 24 November 2020

\section{Check for updates}

(C) Author(s) (or their employer(s)) 2021. Re-use permitted under CC BY-NC. No commercial re-use. See rights and permissions. Published by BMJ.

To cite: Hall KE, Yang $\mathrm{H}$, Goulding DL, et al. Inj Prev 2021;27:i66-i70.

\section{ABSTRACT}

The International Classification of Diseases, $10^{\text {th }}$ Revision, Clinical Modification (ICD-10-CM), implemented in 2015, has more codes than ICD-9-CM for events involving cannabis. We examined cannabis indicator trends across the transition from ICD-9-CM to ICD-10-CM in Colorado, where state law regulates adult cannabis use. Using 2011 to 2018 data from hospital and emergency department (ED) discharges, we calculated monthly rates per 1000 discharges for two indicators: (1) cannabis use disorders and (2) poisoning and adverse effects of psychodysleptics. Immediate, point-of-transition (level) and gradual, post-transition (slope) changes across the ICD-9-CM to ICD-10-CM transition were tested using interrupted time series models adjusted for legalisation, seasonality and autocorrelation. We observed a level increase and slope increase in the rate of ED discharges with cannabis use disorders. Hospital discharges with cannabis use disorders had a negative slope change after the transition and no level change. ED discharges with poisoning and adverse effects of psychodysleptics showed an increase in slope after the transition. No effects of the transition were observed on hospital discharges with poisoning and adverse effects of psychodysleptics. Shifts in the level and slope of cannabis indicator rates after implementation of the new coding scheme suggest the use of caution when interpreting trends spanning the ICD-9-CM to ICD-10-CM transition.

\section{INTRODUCTION}

Adult cannabis use is now legal in 10 states and Washington DC, and over half the states allow medical or decriminalised cannabis use. ${ }^{1}$ In Colorado, medical-use cannabis was legalised in 2000, and retail cannabis was legalised in 2012, with sales beginning in $2014 .^{2-4}$ As more states approve adult-use cannabis laws, it is important to accurately track cannabis-related health outcomes, which may shift in relation to the accessibility, potency and variety of cannabis products available. Hospitalisation and emergency department (ED) discharge data, based on the Uniform Billing 2004 (UB-04) form, provide a population-level data source for surveillance of adverse health encounters involving substance use, ${ }^{5}{ }^{6}$ which Colorado has historically used to measure cannabis legalisation impacts on public health. $^{7-10}$ On 1 October 2015 the USA transitioned from the International Classification of Diseases, $9^{\text {th }}$ Revision, Clinical Modification (ICD-9-CM) to the $10^{\text {th }}$ Revision (ICD-10-CM), greatly expanding both the number and specificity of cannabis-related diagnostic codes. The number of codes related to cannabis use disorders increased from eight codes in ICD-9-CM to 35 in ICD-10-CM, and ICD-10-CM introduced 18 new codes specific to poisoning by, adverse effects of and underdosing of cannabis. Under ICD-9-CM, there were no cannabis-specific poisoning or adverse effects codes. Rather, there were three codes for poisoning by and adverse effects of psychodysleptics, a category encompassing cannabis, lysergide, psilocin, psilocybin, mescaline and other hallucinogens. ${ }^{1112}$

We used interrupted time series (ITS) analysis to examine how the coding transition affected measurement of trends in cannabis-related ED and hospital discharges, hypothesising that the expansion of cannabis-related codes in ICD-10-CM could disrupt trends spanning the transition.

\section{METHODS}

\section{Study population}

We used administrative data reported to the Colorado Hospital Association (CHA) on inpatient and ED discharges from 2011 to $2018 .^{13}$ These data included most acute care discharges from rural, urban, academic and private hospitals in Colorado and did not include discharges from mental health facilities, ambulatory surgical centres, long-term care facilities, military hospitals or other outpatient treatment settings. Colorado residents and nonresidents were included in this analysis. The unit of analysis was the encounter of care (ED or hospital discharge) due to the lack of unique patient identifiers to follow individual patients. ED discharges that resulted in admission to an acute care hospital were included in the hospital discharge data set and excluded from the ED discharge data set making the data sets mutually exclusive. If the ED discharge was admitted or transferred to a non-acute care setting, those discharges remained in the ED data set.

\section{Indicator definitions}

We examined two indicators across the ICD transition: Indicator 1 captured cannabis use disorders, and Indicator 2 captured poisoning by and adverse effects of psychodysleptics. All psychodysleptics were included in Indicator 2 since the lack of cannabis-specific poisoning/adverse effects codes in ICD-9-CM precluded a direct crosswalk to the newly introduced cannabis poisoning/adverse effects codes in ICD-10-CM. The ICD-9-CM and ICD-10-CM codes comprising the indicators are summarised in table 1 with a full listing of codes available in online supplemental appendix $1 .{ }^{11} 12$ 
Table 1 Two indicators examined across the ICD-9-CM to ICD-10-CM transition

\begin{tabular}{|c|c|c|}
\hline Indicators & ICD-9-CM codes included & ICD-10-CM codes included \\
\hline Indicator 1: Cannabis use disorders & $\begin{array}{l}\text { 304.3X - cannabis dependence } \\
305.2 \mathrm{X} \text { - non-dependent cannabis abuse }\end{array}$ & $\begin{array}{l}\text { All F12 codes - cannabis-related disorders (abuse, } \\
\text { dependence, use) }\end{array}$ \\
\hline $\begin{array}{l}\text { Indicator 2: Poisoning and adverse effects of } \\
\text { psychodysleptics }\end{array}$ & $\begin{array}{l}969.6 \text { - poisoning by psychodysleptics } \\
\text { E854.1 - accidental poisoning by psychodysleptics } \\
\text { E939.6 - psychodysleptics causing adverse effects in therapeutic use }\end{array}$ & $\begin{array}{l}\text { T40.7 } \times 1 \mathrm{~A}-\mathrm{T} 40.7 \times 5 \mathrm{~A} \text { - poisoning and adverse effects of } \\
\text { cannabis } \\
\text { T40.8×1A-T40.8×4A - poisoning by lysergide } \\
\text { T40.901A-T40.905A - poisoning and adverse effects of } \\
\text { unspecified psychodysleptics } \\
\text { T40.991A-T40.995A - poisoning and adverse effects of other } \\
\text { psychodysleptics }\end{array}$ \\
\hline
\end{tabular}

ICD-9-CM, International Classification of Diseases, $9^{\text {th }}$ Revision, Clinical Modification; ICD-10-CM, $10^{\text {th }}$ Revision.

The indicators were captured by searching all available code fields $(n=30)$ for any mention of an indicator code. Encounters of care with more than one code within the indicator were only counted once.

\section{Statistical analyses}

The SAS V.9.4 (SAS Institute Inc, Cary, North Carolina) statistical software package was used for all statistical analyses. We performed two analyses to meet our objectives. First, for each indicator, monthly rates per 1000 discharges were calculated separately for ED discharges and hospital discharges from January 2011 to December 2018. We used ITS analysis with segmented regression to test the impact of the transition to ICD-10-CM, considering the interruption point as 1 October $2015 .{ }^{14}$ Our model included an intercept term, a time term (to model the existing trend observed during the ICD-9-CM era), a level shift term at October 2015 (to model the immediate effect of the new coding scheme) and a slope change term after October 2015 (which modelled the change in slope after the transition compared with the pretransition slope). To control for changes in the legal status of cannabis use in Colorado that occurred during the study period (6 November 2012 - legalisation of adult use cannabis, 1 January 2014 - opening of adult use cannabis sales), we tested three models with different variations of legalisation milestones: (1) both level change and slope change terms for each legalisation milestone, (2) only level change for each legalisation milestone and (3) only slope change terms for each legalisation milestone. We selected the third option, modelling legalisation milestones with slope change terms. Further analysis of the impact of legalisation milestones was beyond the scope of this paper.

We tested for fixed seasonal effects after adjusting for lengthof-month variation using SAS Proc X12's F-tests and M7 statistic. Where seasonal patterns were identified, we used the seasonally adjusted time series produced by multiplicative decomposition as our model outcome variable. Where no evidence of seasonality was detected, we used the original time series as our model outcome variable. We used Durbin-Watson tests to detect autocorrelation, and we used SAS Proc AUTOREG with the BACKSTEP option to automatically select the correct order of autoregressive model, through backwards elimination. If the final model contained autoregressive terms, we reported the maximum likelihood estimates with autoregressive terms assumed given. If all autoregressive terms were eliminated from the model, we reported the ordinary least squares estimates. SAS Proc AUTOREG was used to generate predicted values with 95\% CIs. Finally, model fit was checked by examining plots of residuals, white noise probability, autocorrelation function and partial autocorrelation. No issues with the model assumptions and fit were found based on these parameters. Significance was set at an alpha of 0.05 for all model parameters.

\section{RESULTS}

There were 13722815 ED discharges from 1 January 2011 to 31 December 2018 with $0.92 \%$ having a code from Indicator 1 (cannabis use disorders) and $0.04 \%$ having a code from Indicator 2 (poisoning by and adverse effects of psychodysleptics). There were 3810906 hospital discharges from 1 January 2011

Table 2 Interrupted time series model estimates for monthly rates of cannabis use disorders (Indicator 1) and poisoning/adverse effects of psychodysleptics (Indicator 2) per 1000 visits across the ICD-9-CM to ICD-10-CM transition

\begin{tabular}{|c|c|c|c|c|}
\hline & \multicolumn{2}{|c|}{ Indicator 1: Cannabis use disorderst } & \multicolumn{2}{|c|}{$\begin{array}{l}\text { Indicator 2: Poisoning and adverse effects } \\
\text { of psychodysleptics } ¥\end{array}$} \\
\hline & ED & Hospitalisations & ED & Hospitalisations \\
\hline Intercept & $5.8142^{*}$ & $12.5588^{*}$ & $0.2204^{*}$ & $0.2387^{*}$ \\
\hline Time (slope) & 0.0382 & $0.0698^{*}$ & -0.0023 & 0.0031 \\
\hline Adult use cannabis legal slope change (Nov 2012) & $0.2525^{*}$ & $0.3673^{*}$ & $0.0198^{*}$ & 0.0008 \\
\hline Adult use cannabis sales slope change (pre-transition) (Jan 2014) & $-0.4559^{*}$ & $0.1385^{*}$ & $-0.021^{*}$ & 0.0005 \\
\hline Level change at transition (Oct 2015) & $1.9228^{*}$ & $1.759 *$ & -0.0106 & 0.0777 \\
\hline Post-transition slope change & $0.2385^{*}$ & $-0.5424^{*}$ & $0.0125^{*}$ & -0.0021 \\
\hline
\end{tabular}

Data source: Colorado Hospital Association, 1 January 2011 to 31 December 2018.

${ }^{*} p<0.05$.

tIndicator 1: Cannabis use disorders included ICD-9-CM codes 304.3X and 305.2X and all ICD-10-CM F12 codes.

\#Indicator 2: Poisoning and adverse effects of psychodysleptics included ICD-9-CM codes 969.6, E854.1 and E939.6, and ICD-10-CM codes T40.7X1A-T40.7X5A, T40.8X1A-

T40.8X4A, T40.901A-T40.905A and T40.991A-T40.995A.

ED, emergency department; ICD-9-CM, International Classification of Diseases, $9^{\text {th }}$ Revision, Clinical Modification; ICD-10-CM, International Classification of Diseases, $10^{\text {th }}$ Revision, Clinical Modification. 

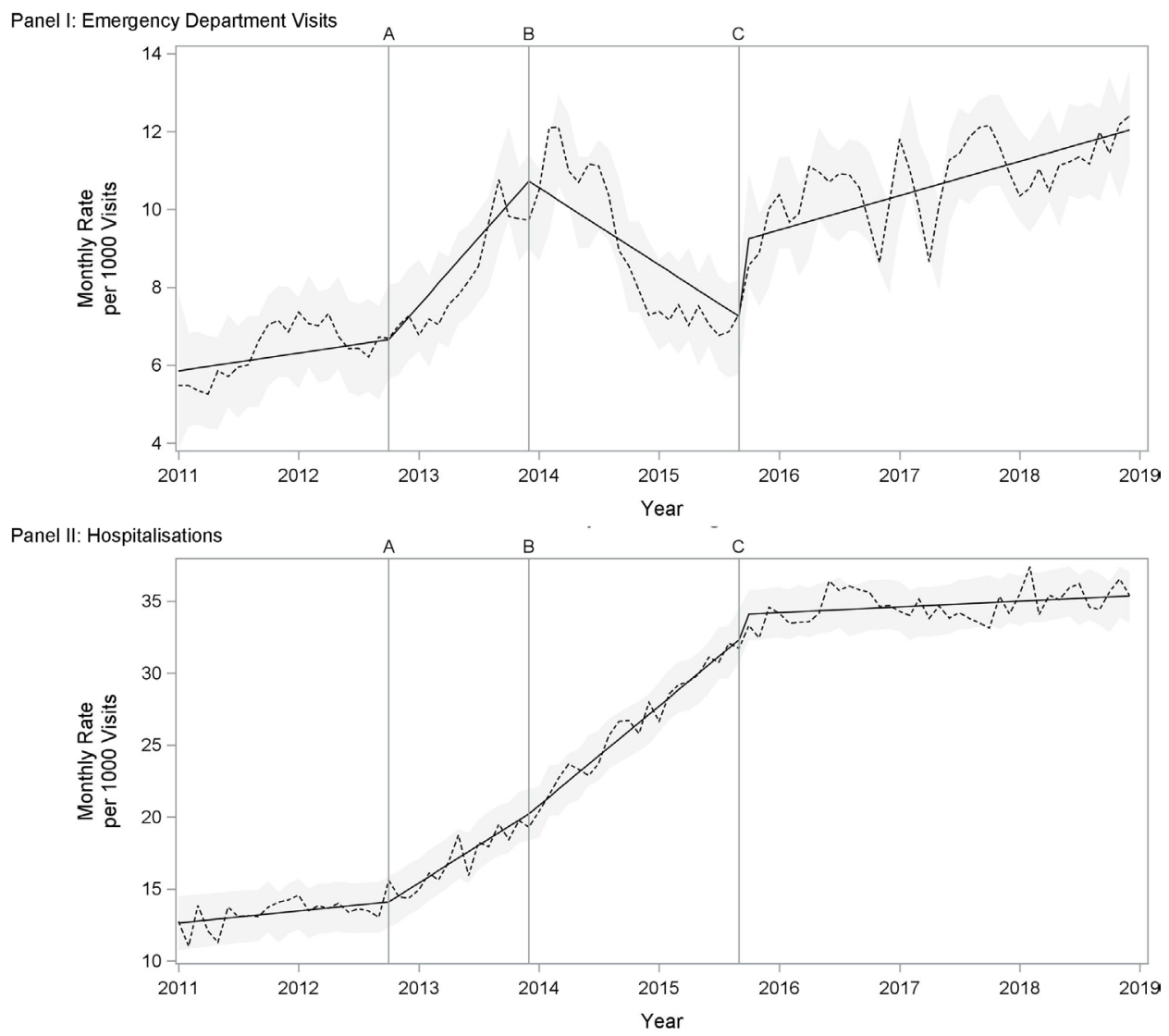

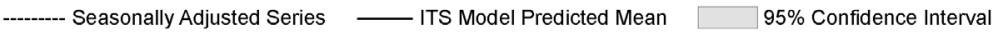

Figure 1 Indicator 1 (cannabis use disorders): Plot of seasonally adjusted observed data and predicted means from interrupted time series model for emergency department discharges (Panel I) and hospital discharges (Panel II), Colorado, 2011 to 2018. (A) November 6, 2012- Legalization of adult use cannabis; (B) January 1, 2014- Opening of adult use cannabis sales; (C) October 1, 2015- Transition to ICD-10-CM. ITS, interrupted time series

to 31 December 2018 with $2.6 \%$ having a code from Indicator 1 (cannabis use disorders) and $0.04 \%$ having a code from Indicator 2 (poisoning by and adverse effects of psychodysleptics). Details on indicator counts by year are provided in online supplemental appendix 2 .

\section{Indicator 1: cannabis use disorders}

We modelled seasonally adjusted monthly rates of cannabis userelated ED and hospital discharges and found that ED discharge rates showed a positive level increase and positive slope change, while hospital discharge rates showed no level change and a negative slope change (table 2 and figure 1 ).

\section{Indicator 2: poisoning by and adverse effects of psychodysleptics}

We modelled monthly rates of ED and hospital discharges related to poisoning by and adverse effects of psychodysleptics, with neither ED nor hospital discharges showing a significant level shift at the transition. Rates of ED discharges showed a positive slope change after the transition (table 2 and figure 2).

\section{DISCUSSION}

When examining Indicator 1 (cannabis use disorders), we found significant positive level shifts in both ED and hospital discharges across the ICD-10-CM transition. ED discharges also showed an increase in slope after the transition, while hospital discharges showed a levelling of the slope after the transition. The positive level shifts observed in both discharge types could be due to the increase in the number of available cannabis-specific substance use disorder codes in ICD-10-CM. In particular, the addition of 12 new codes for cannabis use (F12.9) in ICD-10-CM could inflate the numbers seen after October 2015, since ICD-9-CM only included codes for cannabis abuse and dependence, not cannabis use. However, the new codes do not explain the posttransition slope changes, especially the levelling of the trend line for hospital discharges.

When examining Indicator 2 (poisoning by or adverse effects of psychodysleptics), we found no significant level shift effects on ED or hospital discharges. ED discharges showed a positive change in slope after the transition to ICD-10-CM, which effectively reversed the previously declining trend. Hospital discharges did not show a significant change in slope before and after ICD-10-CM.

The sharp increases in the slope for ED visits seen with both Indicator 1 and Indicator 2 could reflect actual increases in underlying cannabis use in the population and accompanying adverse health events involving cannabis. Poison control data also showed that exposures to cannabis were steady from 2014 through 2015, and began increasing in 2016. ${ }^{15}$ Reasons for this phenomenon are still unknown, however, one theory is that diversification of the adult use cannabis market into newer product types made it easier and more discrete for naive users to try cannabis. The fact that the same pattern was not reflected in hospital discharges could be explained by the typically lower 

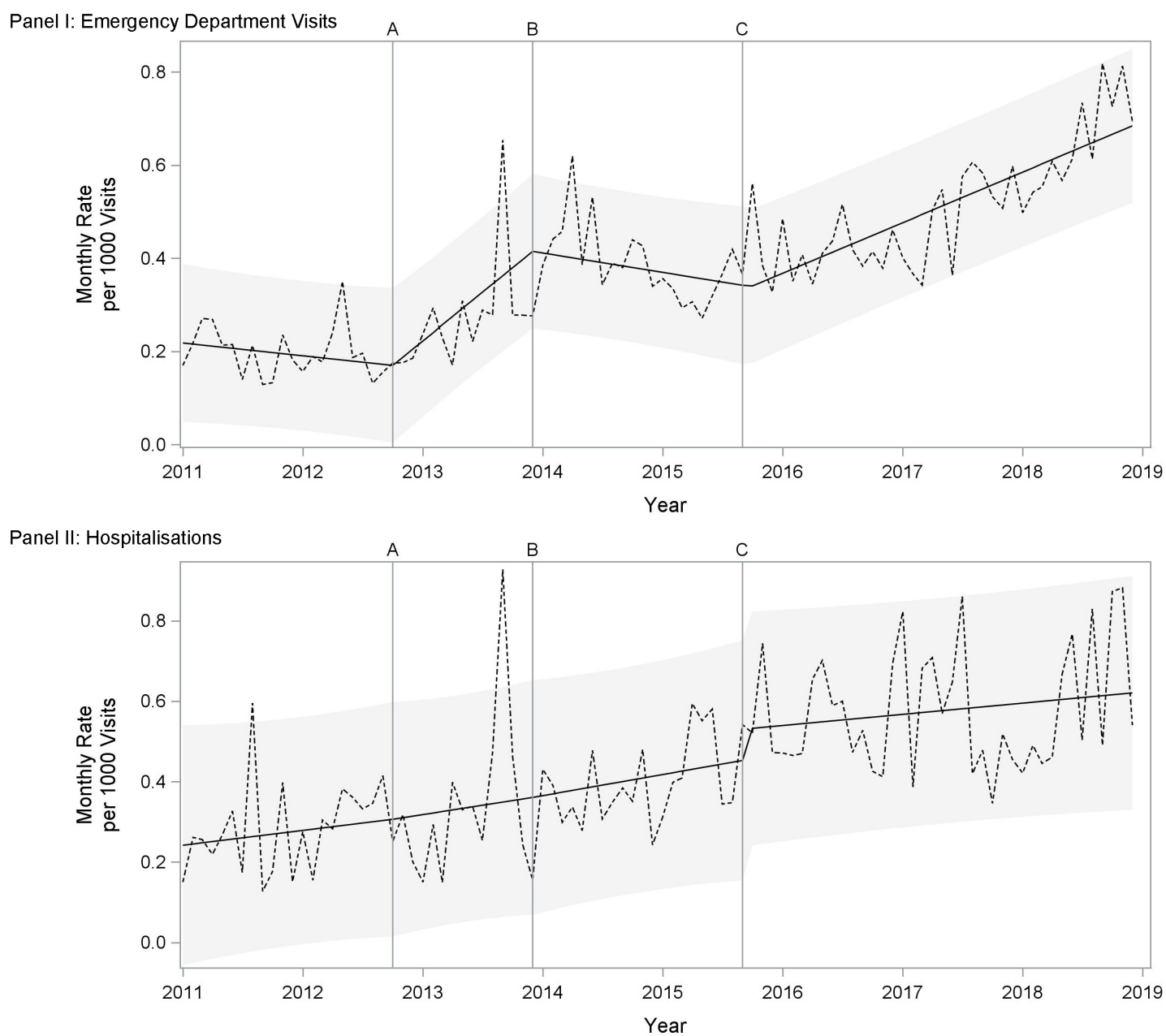

-------- Original Series

ITS Model Predicted Mean

95\% Confidence Interval

Figure 2 Indicator 2 (poisoning by and adverse effects of psychodysleptics): Plot of observed data and predicted means from segmented regression model for emergency department discharges (Panel I) and hospital discharges (Panel II), Colorado, 2011 to 2018. (A) November 6, 2012- Legalization of adult use cannabis; (B) January 1, 2014- Opening of adult use cannabis sales; (C) October 1, 2015- Transition to ICD-10-CM. ITS, interrupted time series.

acuity level of cannabis-related health events that can be resolved in the ED.

These potential explanations pertain only to cannabis, which poses an issue since Indicator 2 also included codes for other psychodysleptics. We found that from 2016 to 2018, 18.1\% of all Indicator 2 codes were codes for other psychodysleptics such as LSD and psilocybin. While there are no reasons to believe there were changes in psychodysleptic use over time, it cannot be ruled out as another possible explanation.

The majority of cannabis ICD-10-CM codes assigned from 2016 to 2018 were cannabis use, followed by abuse, dependence, poisoning and adverse effects codes (online supplemental appendix 3). Among the poisoning by cannabis codes, more than $79 \%$ of both hospital and ED discharges were classified with unintentional intent, which likely reflects changes in coding guidelines to assign unintentional when the intent is unknown instead of undetermined. Approximately $1.5 \%$ of ED discharges and $0.5 \%$ of hospital discharges with cannabisrelated codes included adverse effects of cannabis codes. Adverse effects are defined as medication that was prescribed correctly and administered properly, but the patient suffered an adverse health effect. ${ }^{16}$ This is a confusing finding because cannabis cannot be legally prescribed by a medical provider in Colorado, as it remains a federal schedule I drug. It can only be 'medically recommended'. ${ }^{17}$ It is not clear if these adverse effects codes truly described proper use of medically-recommended cannabis resulting in an adverse health outcome, or if providers were interchanging the terms for 'poisoning' and 'adverse effect' in their documentation. The latter subsequently could lead to improper code assignment by medical coders who are bound to assign codes based on the providers' documentation. While adverse effects codes are not included in current standardised drug overdose indicators, it is important to examine the impacts of excluding adverse effects of cannabis as it relates to the state's legal cannabis status as it could potentially miss cannabis poisonings. ${ }^{18} 19$

\section{LIMITATIONS}

Trends in cannabis and psychodysleptic codes across the transition to ICD-10-CM may be actual trends or may result from systematic biasses introduced by the change in coding systems. This analysis did not assess the sensitivity or specificity of cannabis ICD-10-CM codes and therefore cannot quantify effects due to 
the change in coding system verses actual trends in discharges involving cannabis. However, level changes observed at the time of the transition to ICD-10-CM are difficult to explain by other external factors. As ICD-10-CM continues to be used, it is possible changes in coding patterns over time could be from implementation and training on the new coding system. The ICD-10-CM system is complex and coding to include the new information like cannabis intoxication or mental health symptoms may take longer to adopt. Examining these more specific codes individually over time may be biassed by coder learning curves. Despite these limitations, the expansion and increased specificity of cannabis codes in ICD-10-CM will strengthen the ability to conduct surveillance of cannabis-related adverse health events. Over time, it is expected that coding practice will stabilise, and true trends will become apparent. However, trends observed in the early years of the ICD-10-CM coding system should be interpreted with caution.

\section{CONCLUSIONS}

Observed level and slope changes could be due to increased number or specificity of cannabis codes in ICD-10-CM, structural coding differences, coder learning curves or actual changes in substance use patterns and health events over time. When examining cannabis trends crossing the transition, we recommend visually addressing the change in coding schema and using caution with interpretations.

\section{What is already known on the subject}

- Cannabis ICD codes have been used to measure public health impacts of cannabis legalisation.

- The ICD-10-CM (International Classification of Diseases, $10^{\text {th }}$ Revision, Clinical Modification) transition expanded and improved specificity of cannabis codes.

\section{What this study adds}

- The possible impacts of the International Classification of Diseases, $10^{\text {th }}$ Revision, Clinical Modification (ICD-10-CM) coding transition on cannabis indicator trends over time in Colorado, a cannabis legal environment.

- The patterns of ICD-10-CM cannabis codes used in Colorado emergency department and hospital discharge data.

\section{Acknowledgements Kirk Bol, MSPH; Barbara Gabella, MSPH; Matthew Klein, $\mathrm{MPH}$.}

Contributors KEH technical writer. HY statistical analysis and technical writer. DG data manager. EC subject matter expert and data manager. KAJ senior oversight and technical writer.

Funding The authors have not declared a specific grant for this research from any funding agency in the public, commercial or not-for-profit sectors.

Disclaimer The contents of this publication are solely the responsibility of the authors and do not necessarily represent the official views of the CDC in the United States Department of Health and Human Services, the State of Colorado, the State of Kentucky, the State of Maryland or the State of Massachusetts.

Competing interests None declared.

Patient consent for publication Not required.

Provenance and peer review Commissioned; externally peer reviewed.

Supplemental material This content has been supplied by the author(s). It has not been vetted by BMJ Publishing Group Limited (BMJ) and may not have been peer-reviewed. Any opinions or recommendations discussed are solely those of the author(s) and are not endorsed by BMJ. BMJ disclaims all liability and responsibility arising from any reliance placed on the content. Where the content includes any translated material, BMJ does not warrant the accuracy and reliability of the translations (including but not limited to local regulations, clinical guidelines, terminology, drug names and drug dosages), and is not responsible for any error and/or omissions arising from translation and adaptation or otherwise.

Open access This is an open access article distributed in accordance with the Creative Commons Attribution Non Commercial (CC BY-NC 4.0) license, which permits others to distribute, remix, adapt, build upon this work non-commercially, and license their derivative works on different terms, provided the original work is properly cited, appropriate credit is given, any changes made indicated, and the use is non-commercial. See: http://creativecommons.org/licenses/by-nc/4.0/.

\section{ORCID iDs}

Katelyn E Hall http://orcid.org/0000-0003-2588-3009

Hannah Yang http://orcid.org/0000-0002-9772-0041

\section{REFERENCES}

1 State laws. Available: https://norml.org/laws [Accessed 29 Nov 2018].

2 Odgen DW. 'Memorandum From Deputy Attorney General David W. Ogden to All United States Attorneys regarding Investigations and Prosecutions in States Authorizing the Medical Use of Marijuana.', 2009. Available: https://www.justice. gov/opa/blog/memorandum-selected-united-state-attorneys-investigations-andprosecutions-states [Accessed 27 Dec 2016]

3 H.B. 10-1284 (CO 2010). Available: http://www.leg.state.co.us/clics/clics2010a/csl. nsf/fsbillcont/0C6B6577EC6DB1E8872576A80029D7E2?0pen\&file=1284_01.pdf

4 Section 16. PERSONAL USE AND REGULATION OF MARIJUANA. Colorado constitution article XVIII. Available: https://advance.lexis.com/api/document/collection/ statutes-legislation/id/611F-67J1-JGBH-B21M-00008-00?cite=Colo.\%20Const.\% 20Art.\%20XVIII\%2C\%20Section\%2016\&context=1000516 [Accessed 18 Aug 2020].

5 Safe States. Consensus recommendations for national and state poisoning surveillance: report from the injury surveillance Work-group (ISW7). Atlanta: Safe States, 2012. http://c.ymcdn.com/sites/www.safestates.org/resource/resmgr/imported/ ISW7 Full Report_3.pdf

6 Council of State and Territorial Epidemiologists. Recommendations for strengthening surveillance and research of marijuana and health outcomes in the United States, 2016. Available: http://c.ymcdn.com/sites/www.cste.org/resource/resmgr/2016PS/16_ CC_02.pdf

7 Hall KE, Bol K, Gabella B, et al. Monitoring Health Concerns Related to Marijuana Colorado Hospital Association (CHA) data, 2019. Available: https://www.colorado. gov/pacific/marijuanahealthinfo/CHA-data [Accessed 26 Dec 2019].

8 Hall KE, Monte AA, Chang T, et al. Mental health-related emergency department visits associated with cannabis in Colorado. Acad Emerg Med 2018;25:526-37.

9 Wang GS, Hall K, Vigil D, et al. Marijuana and acute health care contacts in Colorado. Prev Med 2017;104:24-30.

10 Kim HS, Hall KE, Genco EK, et al. Marijuana tourism and emergency department visits in Colorado. N Engl J Med 2016;374:797-8.

11 Practice Management Information Corporation [PMIC]. International classification of diseases 9th revision clinical modification. Los Angeles, California, 2015: 314.

12 Practice Management Information Corporation [PMIC]. International classification of diseases 10th revision clinical modification, 2016.

13 Colorado Hospital Association. Colorado Hospital association discharge data, 2018. Available: https://cha.com/ [Accessed 18 Aug 2020].

14 Bernal JL, Cummins S, Gasparrini A. Interrupted time series regression for the evaluation of public health interventions: a tutorial. Int J Epidemio/ 2017;46:348-55.

15 Wang GS, Banerji S, Contreras AE, et al. Marijuana exposures in Colorado, reported to regional poison centre, 2000-2018. Inj Prev 2020;26:184-6.

16 Verhovshek J. Poisoning, Adverse Effect, and Underdosing in ICD-10-CM - AAPC Knowledge Center, 2018. Available: https://www.aapc.com/blog/44094-poisoningadverse-effect-underdosing-icd-10/ [Accessed 26 Dec 2019].

17 Section 14. MEDICAL USE OF MARIJUANA FOR PERSONS SUFFERING FROM DEBILITATING MEDICAL CONDITIONS. Colorado constitution article XVIII. Available: https://advance.lexis.com/api/document/collection/statutes-legislation/id/611F-67J1JGBH-B1NX-00008-00? cite=Colo.\%20Const. \%20Art.\%20XVIII\%2C\%20Section\% 2014\&context=1000516 [Accessed 18 Aug 2020].

18 Council of State and Territorial Epidemiologists. ICD-10-CM injury surveillance methods toolkit. Available: https://resources.cste.org/Injury-Surveillance-Methods Toolkit [Accessed 6 Dec 2019].

19 Centers for Disease Control and Prevention. CDC's Opioid Overdose Indicator Support Toolkit: Guidance for Reporting on Opioid-Related mortality, morbidity, and PDMP indicators, Version 3.0, 2018. 